\title{
Molecular insights into the local anesthetic receptor within voltage-gated sodium channels using hydroxylated analogs of mexiletine
}

\author{
Jean-François Desaphy ${ }^{1}{ }^{*}$, Antonella Dipalma ${ }^{1}$, Teresa Costanza $^{1}$, Roberta Carbonara ${ }^{1}$, \\ Maria Maddalena Dinardo ${ }^{1}$, Alessia Catalano ${ }^{2}$, Alessia Carocci ${ }^{2}$, Giovanni Lentini ${ }^{2}$, Carlo Franchini ${ }^{2}$ and \\ Diana Conte Camerino ${ }^{1}$
}

1 Section of Pharmacology, Department of Pharmacobiology, Faculty of Pharmacy, University of Bari, Bari, Italy

${ }^{2}$ Department of Medicinal Chemistry, Faculty of Pharmacy, University of Bari, Bari, Italy

Edited by:

Mohamed Chahine, Laval University,

Canada

Reviewed by:

Georges Christé, INSERM, France

Michael E. O'Leary, Jefferson

University, USA

*Correspondence:

Jean-François Desaphy, Sezione di

Farmacologia, Dipartimento

Farmaco-Biologico, Facoltà di

Farmacia, Università degli Studi di

Bari "Aldo Moro," via Orabona

4 - Campus, I-70125 Bari, Italy.

e-mail: jfdesaphy@farmbiol.uniba.it
We previously showed that the $\beta$-adrenoceptor modulators, clenbuterol and propranolol, directly blocked voltage-gated sodium channels, whereas salbutamol and nadolol did not (Desaphy et al., 2003), suggesting the presence of two hydroxyl groups on the aromatic moiety of the drugs as a molecular requisite for impeding sodium channel block. To verify such an hypothesis, we synthesized five new mexiletine analogs by adding one or two hydroxyl groups to the aryloxy moiety of the sodium channel blocker and tested these compounds on hNav1.4 channels expressed in HEK293 cells. Concentration-response relationships were constructed using 25-ms-long depolarizing pulses at $-30 \mathrm{mV}$ applied from an holding potential of $-120 \mathrm{mV}$ at $0.1 \mathrm{~Hz}$ (tonic block) and $10 \mathrm{~Hz}$ (use-dependent block) stimulation frequencies. The half-maximum inhibitory concentrations $\left(\mathrm{IC}_{50}\right)$ were linearly correlated to drug lipophilicity: the less lipophilic the drug, minor was the block. The same compounds were also tested on F1586C and Y1593C hNav1.4 channel mutants, to gain further information on the molecular interactions of mexiletine with its receptor within the sodium channel pore. In particular, replacement of Phe1586 and Tyr1593 by non-aromatic cysteine residues may help in the understanding of the role of $\pi-\pi$ or $\pi$-cation interactions in mexiletine binding. Alteration of tonic block suggests that the aryloxy moiety of mexiletine may interact either directly or indirectly with Phe1586 in the closed sodium channel to produce low-affinity binding block, and that this interaction depends on the electrostatic potential of the drug aromatic tail. Alteration of use-dependent block suggests that addition of hydroxyl groups to the aryloxy moiety may modify high-affinity binding of the drug amine terminal to Phe1586 through cooperativity between the two pharmacophores, this effect being mainly related to drug lipophilicity. Mutation of Tyr1593 further impaired such cooperativity. In conclusion, these results confirm our former hypothesis by showing that the presence of hydroxyl groups to the aryloxy moiety of mexiletine greatly reduced sodium channel block, and provide molecular insights into the intimate interaction of local anesthetics with their receptor.

Keywords: sodium channel, hNav1.4, mexiletine analogs, local anesthetic receptor

\section{INTRODUCTION}

Mexiletine is a class Ib antiarrhythmic drug, also considered as the first choice drug for treating myotonic syndromes (Conte Camerino et al., 2007). Moreover, recent clinical trials demonstrate its therapeutic value to relieve neuropathic pain (Challapalli et al., 2005). Mexiletine exerts its pharmacological action through blockade of voltage-gated sodium channels, thus reducing cell excitability. Preferential binding to inactivated channels and usedependent block are the basis of the selective action of mexiletine on pathologic hyperactive tissues. The structure of mexiletine is related to that of local anesthetic (LA) drugs, presenting a protonable amine group connected to a hydrophobic aromatic ring through an intermediate ether link (Table 1). We have shown that little modification of these three components can substantially affect sodium channel blockade in vitro and antimyotonic effects in vivo (Desaphy et al., 1999, 2001; De Luca et al., 2000, 2003, 2004; De Bellis et al., 2006). The use of mexiletine analogs has allowed to get new important information on the molecular dynamic interaction between the drug and its receptor within the sodium channel pore (De Luca et al., 2000, 2003). Besides, sodium channel mutagenesis experiments have defined the amino acids most probably involved in the interaction with LAs (Ragsdale et al., 1994, 1996; Wright et al., 1998; Nau et al., 1999; Wang et al., 2000; Sunami et al., 2001; Yarov-Yarovoy et al., 2001, 2002; O'Leary and Chahine, 2002; McNulty et al., 2007; Ahern et al., 2008). 
Table 1 | Chemical structures and physicochemical properties.

\begin{tabular}{|c|c|c|c|c|c|c|}
\hline Compound & Structure & $\log P$ & $\mathrm{p} K_{\mathrm{a}}$ & $\log D(p H 7.4)$ & $\begin{array}{l}\text { lonization } \\
\text { (mol\%, pH 7.4) }\end{array}$ & $\begin{array}{l}\text { Electrostatic potential } \\
\text { (kcal/mol) }\end{array}$ \\
\hline Mexiletine & & $2.21 \pm 0.01$ & $9.28 \pm 0.01$ & 0.53 & 98.7 & -50.3 \\
\hline $\mathrm{mHM}$ & OF & $1.67 \pm 0.01$ & $9.04 \pm 0.01$ & 0.02 & 97.7 & -48.0 \\
\hline $\mathrm{pHM}$ & & $1.53 \pm 0.01$ & $8.97 \pm 0.01$ & -0.05 & 97.3 & -50.4 \\
\hline bHMM & $\mathrm{OH}$ & $0.25 \pm 0.05$ & $9.21 \pm 0.03$ & -0.85 & 98.5 & -62.6 \\
\hline pHHMM & & $0.23 \pm 0.02$ & $8.89 \pm 0.02$ & -1.27 & 96.8 & -65.0 \\
\hline
\end{tabular}

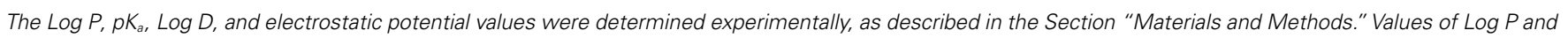
$p K_{a}$ are given as mean \pm SEM. Ionization of the amine group at $p H 7.4$ was calculated from Henderson-Hasselbalch equation, lonization $=1-10^{\left(p H-p K_{a}\right)}$.

In a previous study, we showed that drugs known as modulators of $\beta$-adrenergic receptors are able to block sodium channels in a manner reminiscent of LA drugs (Desaphy et al., 2003). The $\beta$-agonist clenbuterol and the $\beta$-blocker propranolol showed efficacies comparable to mexiletine in producing use-dependent inhibition of sodium currents in rat skeletal muscle fibers as well as in tsA201 cells transiently expressing the human muscle sodium channel isoform, hNav1.4. In contrast, the $\beta$-agonist salbutamol and the $\beta$-blocker nadolol had no effect on sodium currents at $1 \mathrm{mM}$ concentration. Examination of chemical structures and physicochemical properties of these drugs revealed the presence of the two pharmacophores important for sodium channel blocking activity, the amine group and the aromatic ring, which respectively confer a high $\mathrm{p} K_{\mathrm{a}}$ and high lipophilicity. However, the two inactive compounds were characterized by the presence of two hydroxyl groups on the aromatic moiety, which we proposed to be determinant for impeding sodium channel blockade.

To verify this hypothesis, we have synthesized new analogs of mexiletine by introducing one or two hydroxyl groups on the aryloxy moiety of the drug and tested them on sodium currents in mammalian cells permanently transfected with hNav1.4. Moreover site-directed mutagenesis was performed to introduce nonaromatic cysteine residues in place of the Phe1586 and Tyr1593 residues of hNav1.4, which are thought to be part of the binding site for LAs within the domain IV segment 6 of sodium channels (Ragsdale et al., 1994).
The results demonstrate that the presence of hydroxyl groups on the aromatic moiety drastically reduces the ability of compounds to block sodium channels and provide further insight in the molecular interaction between LA drugs and their binding site within the sodium channel pore.

\section{MATERIALS AND METHODS SITE-DIRECTED MUTAGENESIS AND EXPRESSION OF RECOMBINANT SODIUM CHANNELS}

Full-length cDNA encoding the main $\alpha$-subunit of wild-type (WT) skeletal muscle isoform of voltage-gated sodium channel (hNav1.4) was subcloned in the mammalian expression vector pRc-CMV. The two hNav1.4 mutants, F1586C and Y1593C, were engineered by standard two-step PCR-based site-directed mutagenesis. All PCR reactions were performed using Pfu DNA polymerase (Stratagene, La Jolla, CA, USA) for high-fidelity amplification (Desaphy et al., 2010). The complete coding region of channel mutant cDNAs was sequenced to exclude any polymerase errors. Permanent sodium channel expression was achieved by transfecting $1 \mathrm{mg} \mathrm{ml}^{-1}$ of plasmid in human embryonic kidney HEK293 cells using the calcium phosphate precipitation method and clone selection using geneticin (Gibco-Invitrogen, Milan, Italy).

\section{SODIUM CURRENT MEASUREMENT IN HEK293 CELLS}

Whole-cell sodium currents $\left(I_{\mathrm{Na}}\right)$ were recorded at room temperature $\left(20-22^{\circ} \mathrm{C}\right)$ using an Axopatch 1D amplifier (Axon 
Instruments, Union City, CA, USA). Voltage clamp protocols and data acquisition were performed with pCLAMP 9.2 software (Axon Instruments) through a 12-bit A-D/D-A interface (Digidata 1340, Axon Instruments). Pipettes made with Corning 7052 glass (Garner Glass, Claremont, CA, USA) had resistance that ranged from 1 to $3 \mathrm{M} \Omega$. Currents were low-pass filtered at $2 \mathrm{kHz}(-3 \mathrm{~dB})$ by the four-pole Bessel filter of the amplifier and digitized at $10-20 \mathrm{kHz}$. After the patch membrane had been ruptured, a $25-\mathrm{ms}$-long test pulse to $-30 \mathrm{mV}$ from a holding potential (HP) of $-120 \mathrm{mV}$ was applied to the cell at a low frequency until stabilization of $I_{\mathrm{Na}}$ amplitude and kinetics was achieved (typically $5 \mathrm{~min}$ ). Only those data obtained from cells exhibiting series resistance errors $<5 \mathrm{mV}$ were considered for analysis. Little $(<5 \%)$ or no rundown was observed within the experiments. The concentration-response relationships were produced by obtaining the peak current amplitude measured in the presence of drug ( $\left.I_{\text {DRUG }}\right)$, normalized to the peak current amplitude measured in the same cell before drug application $\left(I_{\mathrm{CTRL}}\right)$, as a function of drug concentration [DRUG]. Each data point is the mean \pm SEM from at least three cells. The relationships were fitted with a first-order binding function:

$I_{\mathrm{DRUG}} / I_{\mathrm{CTRL}}=I_{\max } /\left[1+\exp \left([\mathrm{DRUG}] / \mathrm{IC}_{50}\right)^{\mathrm{nH}}\right]$

where $\mathrm{IC}_{50}$ is the half-maximum inhibitory concentration, and $n_{\mathrm{H}}$ is the slope factor. The variable $I_{\max }$ was introduced only for doseresponse relationships of compounds effects on Y1593C channel mutant at $10 \mathrm{~Hz}$, otherwise $I_{\max }$ was fixed to 1 .

\section{MUTANT CYCLE ANALYSIS}

Mutant cycle analysis was performed to evaluate the cross influence between amino acid mutations in the hNav1.4 channel and hydroxyl substitutions in mexiletine, in order to characterize the molecular interactions. The coupling energy $\Delta G$ is thus calculated as $R T \cdot \ln \Omega$, where $R$ is the perfect gas constant $\left(8.314 \mathrm{~J} \mathrm{~K} \mathrm{~mol}^{-1}\right), T$ is the temperature expressed in Kelvin $\left(295.15 \mathrm{~K}=22^{\circ} \mathrm{C}\right.$ ), and $\Omega$ is the coupling constant (Hidalgo and MacKinnon, 1995).

\section{DRUGS AND SOLUTIONS}

Patch clamp pipette solution contained in mM: $120 \mathrm{CsF}, 10$ $\mathrm{CsCl}, 10 \mathrm{NaCl}, 5 \mathrm{EGTA}$, and 5 HEPES, and the $\mathrm{pH}$ was set to 7.2 with $\mathrm{CsOH}$. Bath solution for patch clamp recordings contained (in $\mathrm{mM}$ ): $150 \mathrm{NaCl}, 4 \mathrm{KCl}, 2 \mathrm{CaCl}_{2}, 1 \mathrm{MgCl}_{2}, 5$ HEPES, and 5 glucose. The $\mathrm{pH}$ was set to 7.4 with $\mathrm{NaOH}$. Mexiletine hydrochloride [Mex, 1-(2,6-dimethylphenoxy)propan2-amine] was purchased from Sigma (Milan, Italy). The hydroxylated analogs of mexiletine \{metahydroxymexiletine, mHM, 3-(2-aminopropoxy)-2,4-dimethylphenol; parahydroxymexiletine, pHM, 4-(2-aminopropoxy)-3,5-dimethylphenol; hydroxymethylmexiletine, HMM, [2-(2-aminopropoxy)-3-methy lphenyl]methanol; bis(hydroxymethyl)mexiletine, bHMM, [2(2-aminopropoxy)-1,3-phenylene]dimethanol; parahydroxyhydroxymethyl mexiletine, pHHMM, 4-(2-aminopropoxy)-3(hydroxymethyl)-5-methylphenol $\}$ were synthesized in our laboratories (Catalano et al., 2004, 2010; Cavalluzzi et al., 2007). All drugs were dissolved directly in external patch solution at the desired final concentration. The patched cell was continuously exposed to a stream of control or drug-supplemented bath solution flowing out from a plastic capillary.

\section{EXPERIMENTAL DETERMINATION OF DRUG PHYSICOCHEMICAL PROPERTIES}

The $\mathrm{p} K_{\mathrm{a}}$ and $\log P$ values of mexiletine and its analogs were determined with a potentiometric method using Sirius Glp $K_{\mathrm{a}}$ (Sirius Analytical Instrument Ltd., Forest Row, East Sussex, UK) as described previously (Catalano et al., 2010). Because the compounds showed a low water solubility, methanol was used as co-solvent (methanol-water $10-30 \% \mathrm{w} / \mathrm{w}$ ) for the determination of $\mathrm{p} K_{\mathrm{a}}$.

The electrostatic potential of each analog was determined as the molecular charge distribution of the corresponding methyl ether moiety [2,6-dimethylphenyl methyl ether, for Mex; 3-methoxy2,4-dimethylphenol, for mHM; 4-methoxy-3,5-dimethylphenol, for pHM; (2-methoxy-3-methylphenyl)methanol, for HMM; (2methoxybenzene-1,3-diyl)dimethanol, for bHMM; 3-(hydroxy methyl)-4-methoxy-5-methylphenol, for pHHMM] was investigated. Molecular models were constructed by fragments offered by SPARTAN PRO (Wavefunction, Inc., 18401 Von Karman Avenue, Suite 370, Irvine, CA 92715, USA) inner fragment library and assuming the suggested default starting geometries. The generated geometries were optimized by the molecular mechanics MMFF routine proposed by the software and then submitted to a systematic conformer distribution analysis. Conformers were classified according to the $a b$ initio gas phase energy content calculated at the HF/3-21G* level. All conformers falling within a window of $5 \mathrm{kcal} / \mathrm{mol}$ above global minimum were retained. After removal of conformers differing for dihedral values lower than $10^{\circ}$, the retained conformers were submitted to HF/3-21G* geometry optimization. The most negative electrostatic potential (i.e., the highest energy of interaction with a positive charge used as a probe) value for the most stable conformer of each analog was used for structure-activity relationship considerations.

\section{RESULTS}

\section{EFFECTS OF MEXILETINE AND ANALOGS ON WILD-TYPE hNav1.4 CHANNELS}

To compare the effects of mexiletine and its hydroxylated analogs, block of sodium channels was evaluated by measuring the druginduced reduction of $I_{\mathrm{Na}}$ elicited at $-30 \mathrm{mV}$ for $25 \mathrm{~ms}$ every 10 $(0.1 \mathrm{~Hz})$ or $0.1(10 \mathrm{~Hz}) \mathrm{s}$ from the $\mathrm{HP}$ of $-120 \mathrm{mV}$. Applying this protocol in the absence of drug, there was no significant change in current amplitude for hNav1.4 channels (not shown). Typical time course of peak $I_{\mathrm{Na}}$ amplitude during application of $100 \mu \mathrm{M}$ mexiletine is illustrated in Figure 1A. At the stimulation of $0.1 \mathrm{~Hz}$, application of mexiletine reduced gradually $I_{\mathrm{Na}}$ down to a plateau. This block will be called tonic block hereafter. It is due mainly to the block of closed channels with low affinity, but depends also in part on the block of closed-state inactivated channels with high affinity (Desaphy et al., 2001, 2004). Then increasing the stimulation to $10 \mathrm{~Hz}$ further induced the reduction of $I_{\mathrm{Na}}$ to a lower level, determining the so-called use-dependent block, which depends 


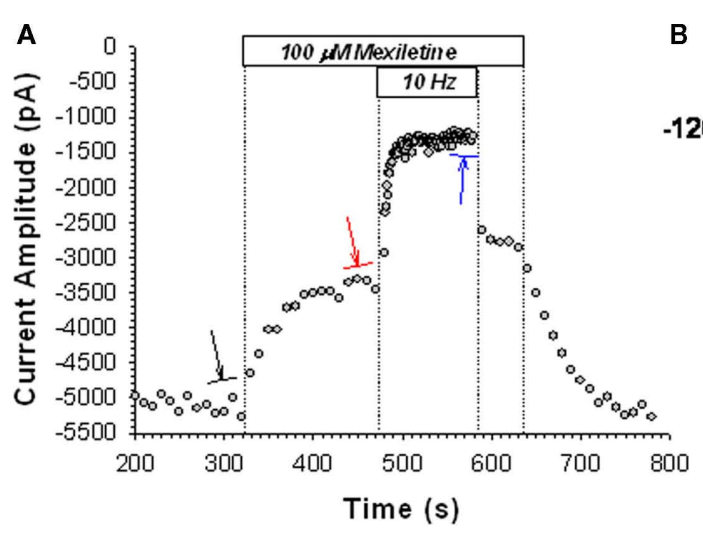

B

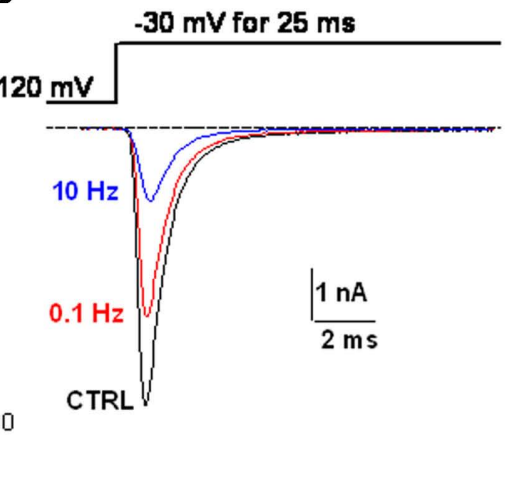

FIGURE 1 | Effects of $100 \mu \mathrm{M}$ mexiletine on hNav1.4 currents. (A) Time course of sodium current amplitude measured in a representative HEK293 cell permanently transfected with hNav1.4 sodium channel subtype before, during, and after of application of $100 \mu \mathrm{M}$ mexiletine. The sodium current was elicited by depolarizing the cell membrane to $-30 \mathrm{mV}$ for $25 \mathrm{~ms}$ every 10
$(0.1 \mathrm{~Hz})$ or $0.1 \mathrm{~s}(10 \mathrm{~Hz})$, from a holding potential of $-120 \mathrm{mV}$. (B) Typical sodium current traces are shown, which were obtained from the average of three records obtained at steady state in absence of drug using $0.1 \mathrm{~Hz}$ stimulation frequency (CTRL), and in presence of drug at $0.1 \mathrm{~Hz}$ (red) and $10 \mathrm{~Hz}$ (blue). on the high-affinity binding to inactivated channels. These effects were fully reversible. Examples of current traces recorded at steady state before (control) and in the presence of $100 \mu \mathrm{M}$ mexiletine at $0.1 \mathrm{~Hz}$ then $10 \mathrm{~Hz}$ are illustrated in Figure 1B. The reduction of $I_{\mathrm{Na}}$ induced by $100 \mu \mathrm{M}$ mexiletine was 32 and $74 \%$ at 0.1 and $10 \mathrm{~Hz}$, respectively.

The same protocol was used to test all the exploratory compounds at various concentrations. Figure 2 shows representative current traces recorded at 0.1 and $10 \mathrm{~Hz}$ stimulation during application of $1 \mathrm{mM}$ of each compound. Effects of mexiletine and $\mathrm{mHM}$ were quite similar, blocking $I_{\mathrm{Na}}$ by $77 \%$ at $0.1 \mathrm{~Hz}$ and $95 \%$ at $10 \mathrm{~Hz}$. All the other compounds were less potent than mexiletine, following the rank order of potency: $\mathrm{pHM}>\mathrm{HMM}>\mathrm{bHMM}>\mathrm{pHHMM}$. The less potent $\mathrm{pHHMM}$ at $1 \mathrm{mM}$ had no effect at $0.1 \mathrm{~Hz}$ and very little effect at $10 \mathrm{~Hz}$. All the effects were fully reversible (not shown). The peak $I_{\mathrm{Na}}$ amplitude measured in presence of drug at 0.1 or $10 \mathrm{~Hz}$ was normalized with respect to control peak $I_{\mathrm{Na}}$ and reported as a function of drug concentration to draw concentration-response curves (Figure 3). All the curves were satisfactorily fitted with a first-order binding function, given the half-maximum inhibitory concentrations $\left(\mathrm{IC}_{50}\right)$ reported in Table 2 . Addition of one hydroxyl group to mexiletine had different effects on efficacy depending on the position of substituent on the aryloxy moiety, ranging from merely no effect (mHM) to an eightfold increase of $\mathrm{IC}_{50}$ value (HMM) at $0.1 \mathrm{~Hz}$. The addition of two hydroxyl groups induced a dramatic reduction of efficacy by more than 45 times for bHMM and 122 times for $\mathrm{pHHMM}$. The effects of chemical maneuvers were more pronounced at $10 \mathrm{~Hz}$ stimulation, with an increase of $\mathrm{IC}_{50}$ values ranging from 1.7-fold for $\mathrm{mHM}$ to 567 -fold for $\mathrm{pHHMM}$, compared to mexiletine. Thus the $0.1-$ to $10-\mathrm{Hz} \mathrm{IC}_{50}$ ratio decreased from 9.8 for mexiletine to 6.3 for $\mathrm{mHM}$ and about 2.5 for the other compounds.

The most prominent effect of hydroxylation on the physicochemical properties of compounds is a reduction of the lipophilicity at the experimental $\mathrm{pH}$, expressed as the $\log \mathrm{D}$ determined

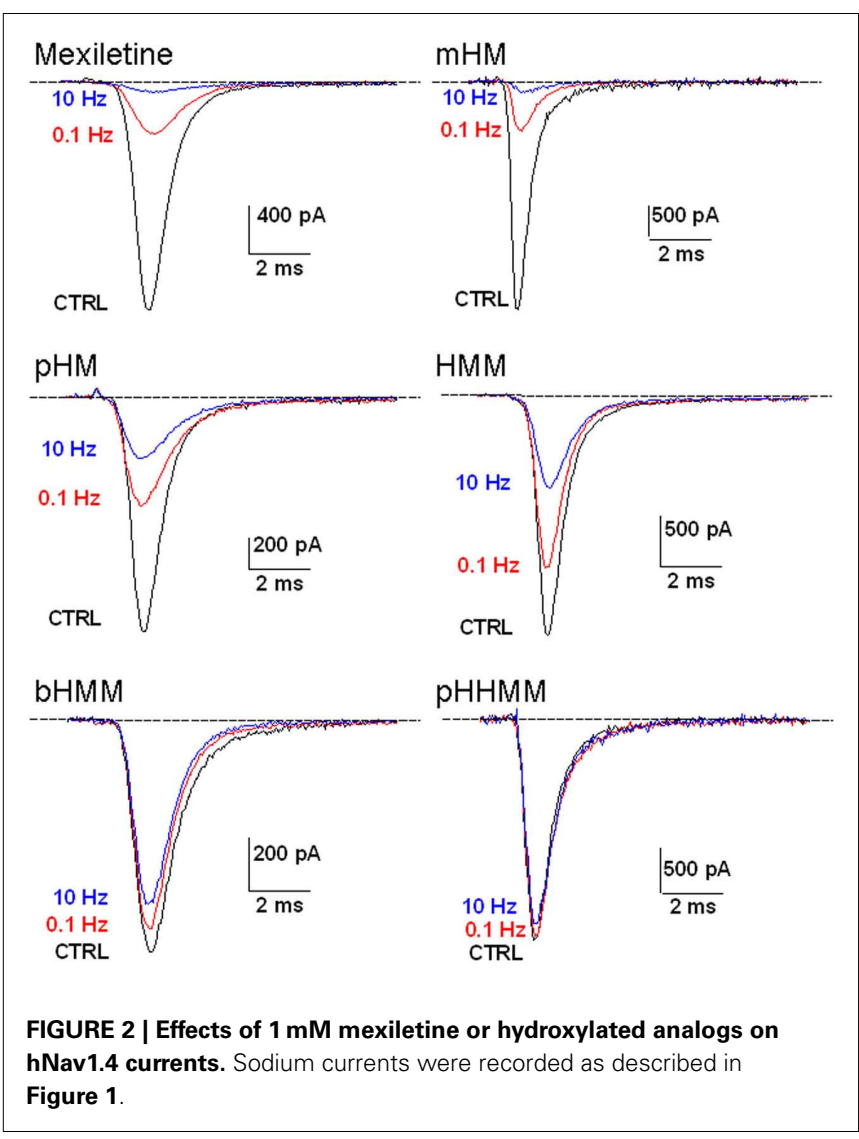

experimentally (Table 1 ). The relationships of $\mathrm{IC}_{50}$ values as a function of $\log P$ or $\log D$, plotted on semilogarithmic axes, were linearly correlated: The higher the lipophilicity, the more efficient was the compound (Figure 4). Notwithstanding, if the lipophilicity was the unique factor influencing compound efficacy, $\mathrm{mHM}$ should have appeared less efficient than it was. 


\section{Wild-type hNav1.4 channel}
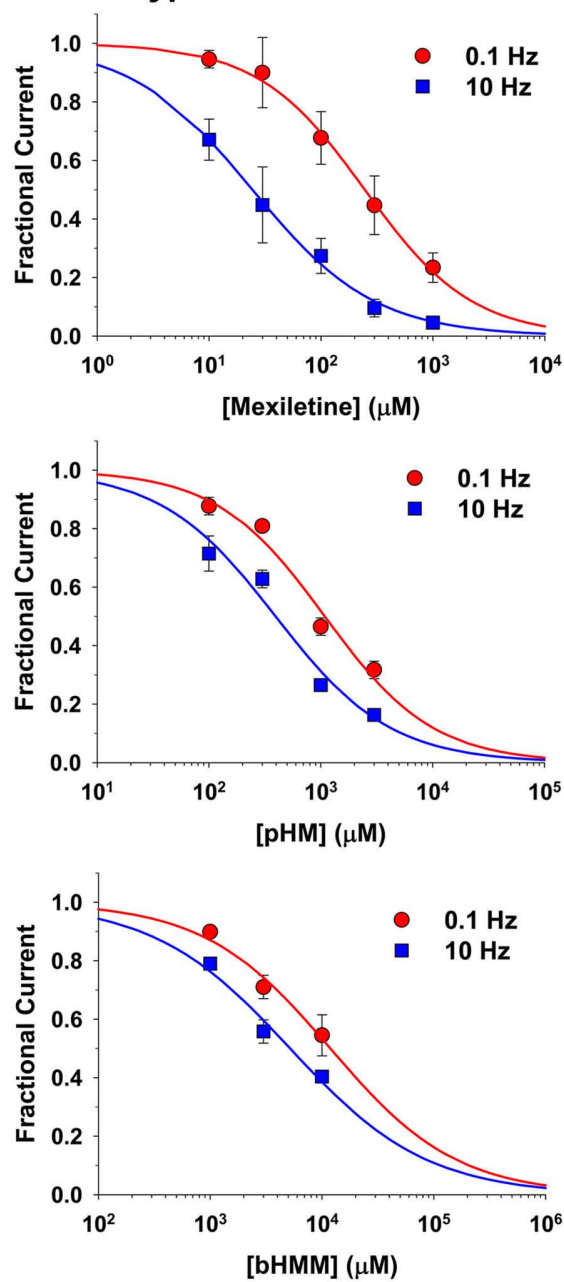

FIGURE 3 | Concentration-response relationships for mexiletine or hydroxylated analogs on hNav1.4 channels. The curves were constructed at 0.1 and $10 \mathrm{~Hz}$ frequency stimulation, and fitted with a first-order binding
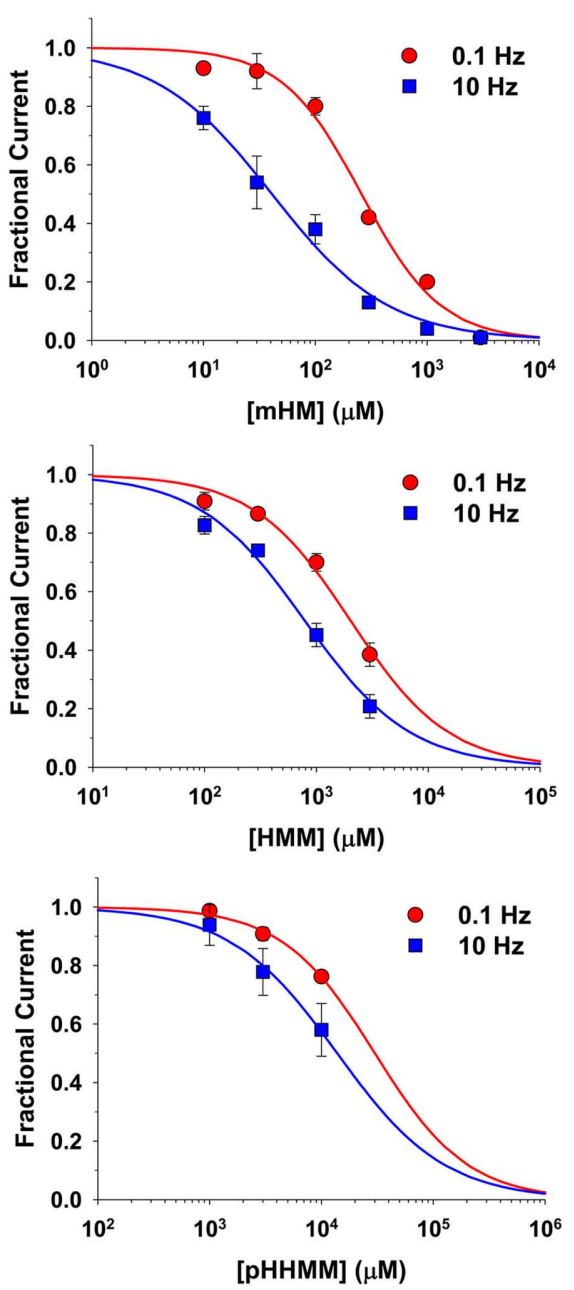

function (Eq. 1 in Materials and Methods). Each point is the mean \pm SEM from at least three cells. The calculated $I_{C_{50}}$ values $\pm S E$ of the fit are reported in Table 2. The slope factors ranged between 0.71 and 1.22 .

\section{EFFECTS OF MEXILETINE AND DERIVATIVES ON F1586C hNav1.4 MUTANT}

Mexiletine is thought to bind the putative high-affinity receptor for LAs within the pore of sodium channels. Indeed, the non-conservative mutation of phenylalanine to cysteine in position 1586 (hNav1.4) within the 6th segment of domain IV drastically reduced mexiletine block of inactivated channels (Desaphy et al., 2009). The hydroxylated compounds, except mHM, were tested on the same sodium channel mutant F1586C. Doseresponse relationships of compound effects on F1586C $I_{\mathrm{Na}}$ are shown in Figure 5, and the $\mathrm{IC}_{50}$ values are reported in Table 2. On FC channels, the compound pHM appeared as much potent as mexiletine, whereas HMM was 2.2 times less efficient, bHMM 15-20 times less, and pHHMM 20-50 times less. Compared to WT channels, the mutation reduced sodium channel block for all the compounds, especially at $10 \mathrm{~Hz}$ stimulation. Indeed usedependence was almost abolished for mexiletine, pHM, HMM, and $\mathrm{bHMM}$, the 0.1 - to $10-\mathrm{Hz} \mathrm{IC}_{50}$ ratio being reduced to 1.2-1.6.
In contrast, use-dependent block of F1586C mutant by pHHMM was maintained.

\section{EFFECTS OF MEXILETINE AND DERIVATIVES ON Y1593C hNav1.4 MUTANT}

Another amino acid potentially involved in the binding of LAlike drugs is the tyrosine in position 1593 of hNav1.4 channel (Desaphy et al., 2010). This residue was proposed to interact with the hydrophobic moiety of sodium channel blockers through a $\pi-\pi$ interaction (Ragsdale et al., 1994), although this hypothesis has been recently challenged (Ahern et al., 2008). We tested our compounds, except mHM, on the Y1593C mutant. Representative $I_{\mathrm{Na}}$ current traces recorded before and after application of $1 \mathrm{mM}$ mexiletine are shown in Figure 6. In contrast to WT and F1586C channels, the Y1593C-mutant $I_{\mathrm{Na}}$ developed significant use-dependent reduction at $10 \mathrm{~Hz}$ in absence of drug, ranging from 15 to $30 \%$ of control current depending on the cell. The doseresponse relationships are shown in Figure 6. To take into account 
Table 2 | Half-maximum inhibitory concentration values $\left(\mathrm{IC}_{50}\right)$.

\begin{tabular}{|c|c|c|c|c|c|}
\hline \multirow[t]{2}{*}{ Drug } & \multirow[t]{2}{*}{ Stimulation frequency } & \multirow{2}{*}{$\begin{array}{l}\text { WT hNav1.4 } \\
\text { IC }_{50}(\mu \mathrm{M})\end{array}$} & \multirow{2}{*}{$\begin{array}{l}\text { F1586C } \\
I_{50}(\mu M)\end{array}$} & \multicolumn{2}{|c|}{ Y1593C } \\
\hline & & & & $\mathrm{IC}_{50}(\mu \mathrm{M})$ & $I_{\max }$ \\
\hline \multirow{2}{*}{ Mexiletine } & $10 \mathrm{~Hz}$ & $24.4 \pm 1.8$ & $1089 \pm 181$ & $169 \pm 94$ & $0.84 \pm 0.17$ \\
\hline & 0.1 -to- $10 \mathrm{~Hz}$ ratio & 10.1 & 1.2 & 2.8 & \\
\hline $\mathrm{mHM}$ & 0.1 -to- $10 \mathrm{~Hz}$ ratio & 6.3 & n.d. & n.d. & \\
\hline \multirow[t]{3}{*}{$\mathrm{pHM}$} & $0.1 \mathrm{~Hz}$ & $1086 \pm 183$ & $1132 \pm 36$ & $908 \pm 30$ & 1 \\
\hline & $10 \mathrm{~Hz}$ & $394 \pm 82$ & $847 \pm 81$ & $626 \pm 45$ & $0.74 \pm 0.02$ \\
\hline & 0.1 -to- $10 \mathrm{~Hz}$ ratio & 2.8 & 1.3 & 1.5 & \\
\hline HMM & $0.1 \mathrm{~Hz}$ & $2028 \pm 255$ & $2994 \pm 74$ & $1638 \pm 14$ & 1 \\
\hline \multirow{2}{*}{ bHMM } & $10 \mathrm{~Hz}$ & $5190 \pm 1021$ & $17296 \pm 2571$ & $10353 \pm 4102$ & $0.78 \pm 0.11$ \\
\hline & $0.1-$ to- $10 \mathrm{~Hz}$ ratio & 2.3 & 1.6 & 1.2 & \\
\hline \multirow[t]{3}{*}{ pHHMM } & $0.1 \mathrm{~Hz}$ & $30073 \pm 7059$ & $67730 \pm 9125$ & $24782 \pm 2161$ & 1 \\
\hline & $10 \mathrm{~Hz}$ & $13845 \pm 2516$ & $21056 \pm 7650$ & $13482 \pm 1304$ & $0.81 \pm 0.03$ \\
\hline & 0.1 -to- $10 \mathrm{~Hz}$ ratio & 2.2 & 3.2 & 1.8 & \\
\hline
\end{tabular}

These values were determined at the holding potential of - $120 \mathrm{mV}$ from the fit of concentration-response curves with the first-order binding Eq. 1 described in

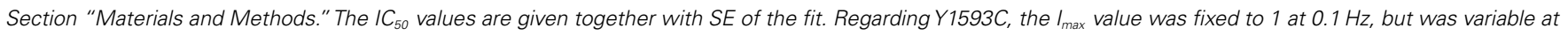
10 Hz. n.d., Not determined.

the use-dependent reduction of Y1593C-mutant $I_{\mathrm{Na}}$ in absence of drugs, an additional variable, namely $I_{\max }$, was introduced in the fitting equation. The $\mathrm{IC}_{50}$ and $I_{\max }$ values are reported in Table 2. Regarding the $\mathrm{IC}_{50}$ values at $0.1 \mathrm{~Hz}$, the $\mathrm{Y} 1593 \mathrm{C}$ mutation was less disturbing than F1586C. Compared to WT, the $\mathrm{IC}_{50}$ of mexiletine on $\mathrm{Y} 1593 \mathrm{C} I_{\mathrm{Na}}$ at $0.1 \mathrm{~Hz}$ was twofold higher, whereas no significant change was observed for the other compounds. In contrast, the Y1593C mutation reduced dramatically use-dependent block at $10 \mathrm{~Hz}$, increasing $\mathrm{IC}_{50}$ sevenfold for mexiletine, and 1.5- to 2fold for the other compounds, except for pHHMM. Compared to WT, the 0.1 - to $10-\mathrm{Hz} \mathrm{IC}_{50}$ ratio decreased to 2.8 for mexiletine and 1-1.5 for the other compounds. No significant effect of Y1593C mutation was observed for $\mathrm{pHHMM}$.

\section{MUTANT CYCLE ANALYSIS}

Being modified solely on the aryloxy moiety, the derivatives of mexiletine can be considered as simple mexiletine mutants. Thus the combined evaluation of effects of mexiletine mutants on hNav1.4 channel mutants allows the calculation of mutant cycles (Hidalgo and MacKinnon, 1995; Lipkind and Fozzard, 2005). By this way, the cross influence of one mutation on the effect of the other can be quantified using a thermodynamic cycle in order to characterize the intimate molecular interactions. Such a mutant cycle analysis is illustrated for pHM in Figure 7, and coupling energies are reported in Table 3. Since the tonic block is determined mainly by interaction of drugs with the closed channel, mutant cycle calculation using the $\mathrm{IC}_{50}$ values for tonic block likely reveals information about interaction of drugs with the lowaffinity binding site (Figure 7A). In these conditions, the coupling energy $(\Delta G)$ for interaction with F1586 is $1 \mathrm{kcal} / \mathrm{mol}$, whereas $\Delta G$ is $0.5 \mathrm{kcal} / \mathrm{mol}$ for interaction with Y1593, thereby suggesting that mexiletine is closer to F1586 than to Y1593 in the closed channel. Since $\mathrm{OH}$ substitutions reduce $\Delta G$ for $\mathrm{F} 1586$ but leave unchanged $\Delta G$ for Y1593, we may hypothesize that the former amino acid may interact directly or indirectly with the aryloxy mexiletine moiety whereas the latter may not be involved in low-affinity binding. On the other hand, mutant cycle calculation using the $\mathrm{IC}_{50}$ values for use-dependent block ( $10 \mathrm{~Hz}$ stimulation) may allow to get information about the interaction of drugs with the high-affinity binding site (Figure 7B). In this case, the coupling energy between the drug and $Y 1593$ is $0.9 \mathrm{kcal} / \mathrm{mol}$, whereas $\Delta G$ is $\sim 1.8 \mathrm{kcal} / \mathrm{mol}$ for F1586, which suggests that mexiletine may interact with both amino acids, and that interaction with F1586 is more critical to high-affinity binding.

\section{DISCUSSION}

In this study, we used chemical maneuvers on mexiletine and sitedirected mutagenesis on hNav1.4 voltage-gated sodium channel to get further insight in the intimate drug-channel interaction at the LA receptor. The binding affinity of LA drugs depends on the state of the channel, being higher for the open/inactivated with respect to the closed channel (Hille, 1977; Fozzard et al., 2011). Please note here that tonic block measured at the stimulation of $0.1 \mathrm{~Hz}$ results from the combination of low-affinity drug binding 

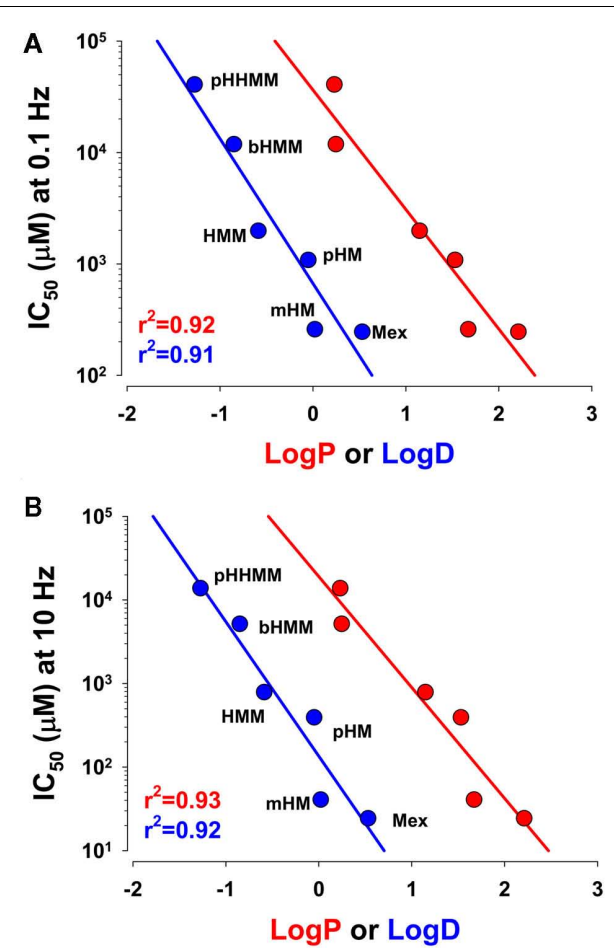

FIGURE 4 | Relationship between IC $_{50}$ values for drug action on hNav1.4 channels and drug lipophilicity expressed either as Log $\boldsymbol{P}$ or $\log \boldsymbol{D}$. The $I \mathrm{C}_{50}$ values were determined at the holding potential of $-120 \mathrm{mV}$ at $0.1 \mathrm{~Hz}(\mathbf{A})$ or $10 \mathrm{~Hz}$ (B) stimulation frequency, as described in Figure 3. The $\log P$ and $\log D$ values were measured as described in Table 1. The points were linearly correlated with $r^{2}>0.9$

to closed channels and, to a lesser extent, high-affinity binding to closed-state inactivated channels, while use-dependent block measured at $10 \mathrm{~Hz}$ stimulation depends mainly on the high-affinity binding to inactivated channels (Desaphy et al., 2001, 2004).

\section{LIPOPHILICITY OF DRUGS IS A KEY DETERMINANT OF SODIUM CHANNEL BLOCKADE}

The results first confirm our former hypothesis (Desaphy et al., 2003), that the presence of two hydroxyl groups on the aryloxy moiety of LA-like drugs impedes high-affinity sodium channel blockade. We also show that the presence of a single hydroxyl group is less deleterious, depending however on the position of the $\mathrm{OH}$ group. The good correlation between the $\log D$ of compounds and the $\mathrm{IC}_{50}$ values, either at 0.1 or $10 \mathrm{~Hz}$, suggests that compound lipophilicity is a major parameter. Because the putative LA receptor lies within the channel pore, lipophilicity might be determinant allowing the compound to reach/escape its receptor through the closed or inactivated channel. For instance, we previously showed that the drug pilsicainide, which has a negative $\log D$, blocks channels inactivated from the closed state with very low efficiency compared to mexiletine, although affinities for inactivated channels of both drugs are comparable (Desaphy et al., 2010). Thus altering hydrophobicity of compounds can modify drug access to or escape from the binding site. A reduced hydrophobicity is expected to reduce drug access to closed channels, which will result in a reduced apparent affinity for the closed and closedinactivated states. Such a mechanism likely contributes significantly to the effects observed in the present study. Nevertheless, such an explanation is not completely sufficient because inhibition of sodium current at $10 \mathrm{~Hz}$ stimulation is greatly reduced as well as use-dependence expressed as $0.1-$ to $-10 \mathrm{~Hz} \mathrm{IC}_{50}$ ratio, arguing against a trapping mechanism of the more hydrophilic compounds within the closed/inactivated channel (O'Leary et al., 2003). This result indicates that lipophilicity is also a critical determinant of the intimate interaction between the compound and its receptor. We thus tried to get more information by using contemporaneously mexiletine analogs and sodium channel mutants.

\section{EFFECTS OF F1586C MUTATION ON SODIUM CHANNEL BLOCKADE BY MEXILETINE AND HYDROXYLATED DERIVATIVES}

The phenylalanine in position 1586 is thought to be a key component of LA drug binding to the LA receptor (Ragsdale et al., 1994; Sheets et al., 2010). The aromaticity of this residue is required for use-dependent inhibition, while its hydrophobicity may be relevant for resting block (Li et al., 1999). By incorporating unnatural fluorinated phenylalanine analogs in place of the natural phenylalanine, it was recently demonstrated that disruption of the electrostatic potential at this position abolishes use-dependent inhibition without affecting resting block by lidocaine and mexiletine (Ahern et al., 2008; Pless et al., 2011). Since the fluorination did not affect blockade by the neutral benzocaine, the authors concluded that a $\pi$-cation interaction between phenylalanine side chain and the charged amine of drugs is a key player in high-affinity binding, at least for class Ib antiarrhythmics such as mexiletine (Pless et al., 2011). Accordingly, we observed that the mutation of F1586 by a non-aromatic cysteine nearly zeroed use-dependent inhibition by mexiletine and its derivatives, except pHHMM. In addition, we found that low-affinity block by mexiletine was also lightly affected by $\mathrm{F} 1586 \mathrm{C}$, because the $\mathrm{IC}_{50}$ value calculated at $0.1 \mathrm{~Hz}$ stimulation was $50 \%$ greater than mexiletine affinity for WT channels in the closed state $(\sim 800 \mu \mathrm{M}$, Desaphy et al., 2001).

Interestingly, the inhibition of F1586C by pHM and mexiletine was comparable, indicating that the presence of one hydroxyl group in pHM mainly reduced high-affinity, use-dependent block of WT channels (as in $\mathrm{mHM}$ ). Considering the $\pi$-cation interaction with F1586 as the main determinant of high-affinity binding, this suggests that alteration of the aryloxy moiety by introduction of the $\mathrm{OH}$ in $\mathrm{mHM}$ and $\mathrm{pHM}$ is able to weaken the critical interaction of the charged amine with F1586, through a mechanism resembling cooperativity between two pharmacophores. Our results suggest that this may be related to the reduction of drug lipophilicity (see Log $D$ value in Table 1). Nevertheless, it has been recently shown that addition of a methyl group in para position of lidocaine is also able to weaken the $\pi$-cation interaction with F1586 (see supplemental data in Pless et al., 2011), suggesting that changes other than lipophilicity may be also involved. As hypothesized from previous experiments using aryloxy-substituted mexiletine analogs (Franchini et al., 2003), a possibility is that the presence of substituents on the aromatic ring may slightly modify the orientation of the molecule, thereby weakening the $\pi$-cation interaction. It is also interesting that while the overall hydrophobicity does not change between $\mathrm{mHM}$ and $\mathrm{pHM}$, the $\mathrm{IC}_{50}$ for 


\section{F1586C hNav1.4 channel mutant}
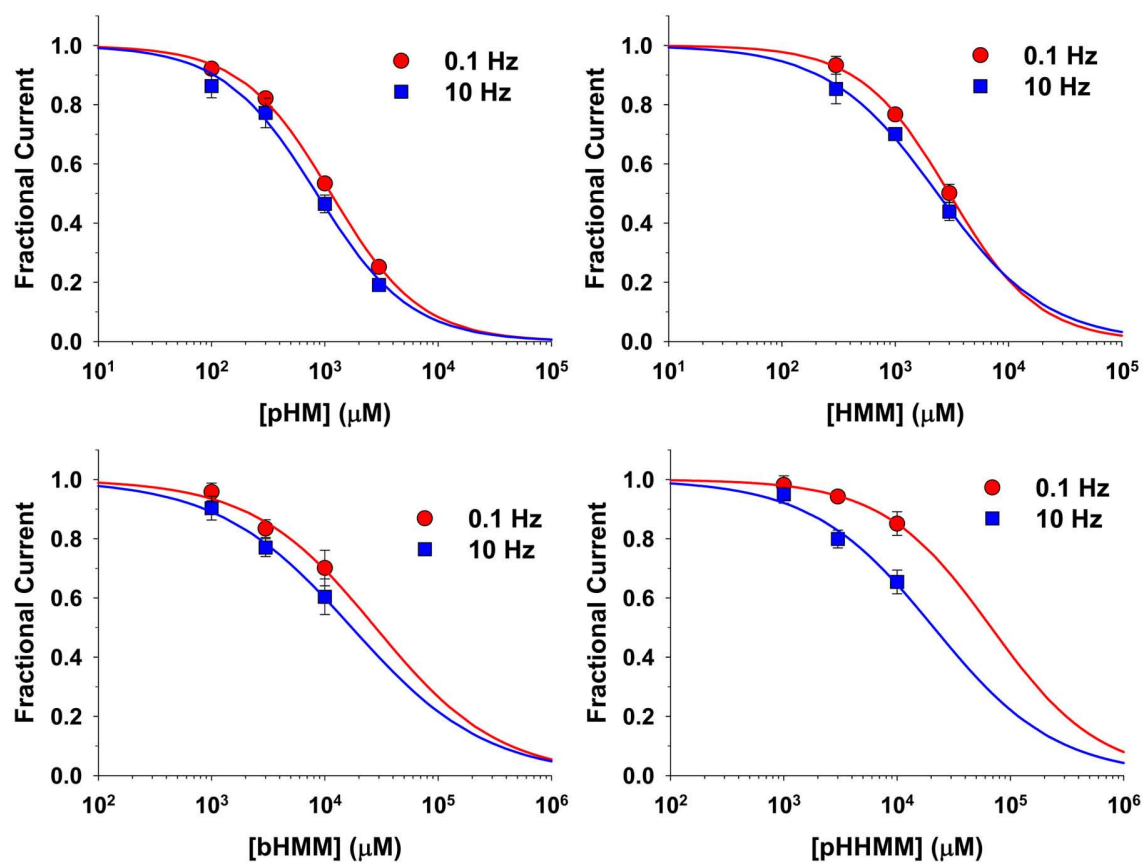

FIGURE 5 | Concentration-response relationships for hydroxylated mexiletine analogs on F1586C hNav1.4 channel mutants. The curves were constructed at 0.1 and $10 \mathrm{~Hz}$ frequency stimulation, and fitted with a first-order binding function (Eq. 1 in Materials and Methods). Each point is the mean \pm SEM from at least three cells. The calculated $I C_{50}$ values $\pm S E$ of the fit are reported in Table 2. The slope factors ranged between 0.74 and 1.11. use-dependent block of WT channels decreases 10-fold with the $\mathrm{OH}$ in para position, thereby confirming that not only lipophilicity is involved. Thus, in function of its position, the substituent may modify more or less the orientation of the entire molecule within the binding site. It is possible to appreciate from Figure 8 how $\mathrm{OH}$ addition in meta have limited effects on aryloxy hindrance and on electrostatic distribution within the aryloxy (compared to mexiletine), whereas the $\mathrm{OH}$ in para concentrates more electronegativity close to the molecule extremity and induces a major steric hindrance. We may speculate that, in case of $\pi-\pi$ stacking between the aryloxy and Y1593 side chain (see below), the $\mathrm{OH}$ in para position as in pHM may interact very negatively with the $\mathrm{OH}$ in Y1593, whereas the $\mathrm{OH}$ in meta position may be less unfavorable. The former negative interaction may result from steric hindrance or local electrostatic repulsion between the two $\mathrm{OH}$.

When the strong interaction between the charged amine group and F1586 is disrupted by cysteine substitution, pHM has nearly the same activity than mexiletine even if it displays a reduced $\log D$. This latter observation suggests that an additional $\mathrm{OH}$, as in $\mathrm{mHM}$ and $\mathrm{pHM}$, or substitution of $\mathrm{F} 1586$ have no additive effect on low-affinity binding. Such an observation would be in accord with the proposed horizontal orientation of LA drugs in the closed channel, where the aromatic moiety of drugs may be exposed toward F1586 (Bruhova et al., 2008; Hanck et al., 2009; Sheets et al., 2010). Thus the alteration of one or the other may determine similar effect on low-affinity binding.

Interestingly, we noted that $\mathrm{mHM}$ and $\mathrm{pHM}$ show an electrostatic potential similar to that of mexiletine (Figure 8). In addition we calculated the value of energy coupling for tonic block calculated from mexiletine/pHM and F1586C mutants cycle, which resulted close to $1 \mathrm{kcal} / \mathrm{mol}$ (Table 3 ), being in the range expected for a through-space electrostatic coupling (Hidalgo and MacKinnon, 1995). Altogether, these results suggest that the aromatic moiety of the drug may interact with F1586 in the closed channel through $\pi-$ $\pi$ stacking thereby accounting for low-affinity binding. It should be noted however that, in contrast with this hypothesis, the variation of F1586 electrostatic potential by fluorination was shown to have no effect on low-affinity binding of lidocaine (Ahern et al., 2008). Thus an alternative hypothesis to be considered may be an indirect effect of F1586C mutation, through an allosteric mechanism, on the electrostatic coupling between the aryloxy drug moiety and another aromatic residue in the closed pore.

Regarding HMM and bHMM, a similar impairment of positive cooperativity between the aromatic and protonable drug extremities may account for the reduction of high-affinity blockade of WT channels, and use-dependent block was also nearly zeroed by the F1586C mutation. Moreover, tonic block of WT channels by HMM and bHMM was greatly reduced compared to that exerted by mexiletine. Thus the $\mathrm{IC}_{50}$ values for tonic block by HMM and bHMM were more than 2- and 10-fold higher than the specific affinity of mexiletine for closed channels, respectively $(\sim 800 \mu \mathrm{M}$, Desaphy et al., 2001), indicating that these compounds significantly affect the low-affinity binding. Interestingly, we observed that the electrostatic potentials of the aryloxy moiety of HMM and $\mathrm{bHMM}$ were $10-\mathrm{kcal} / \mathrm{mol}$ more negative than that of mexiletine, $\mathrm{mHM}$, and $\mathrm{pHM}$. We may thus hypothesized that alteration 
Y1593C hNav1.4 channel mutant
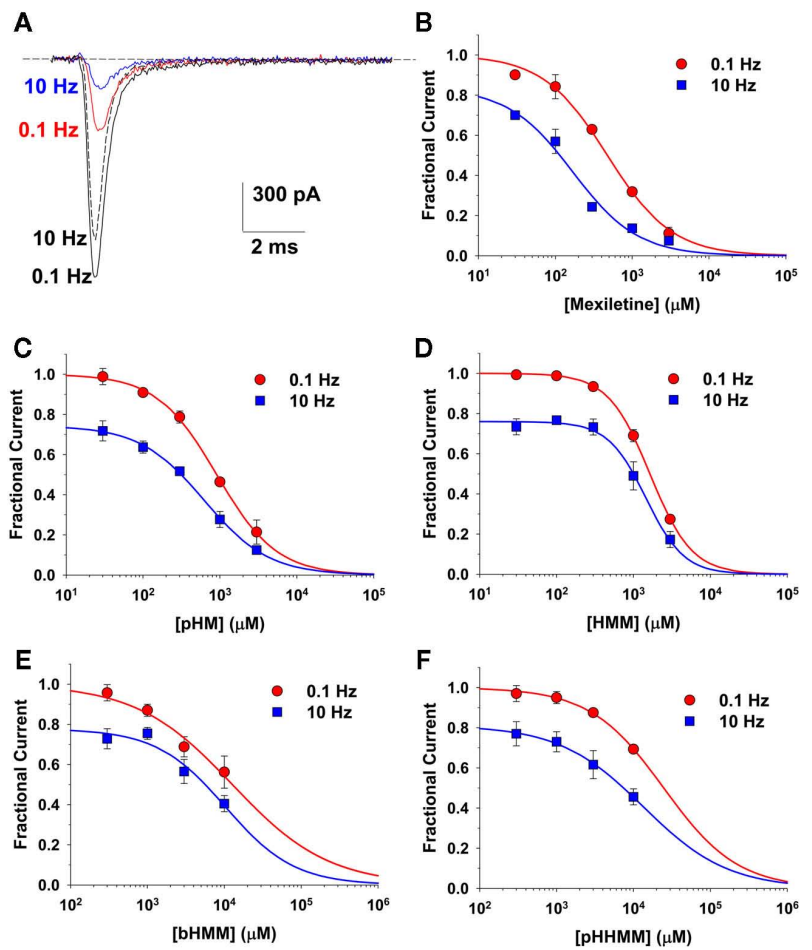

FIGURE 6 | Concentration-response relationships for mexiletine and hydroxylated analogs on $\mathrm{Y} 1593 \mathrm{C}$ hNav1.4 channel mutants. (A) Representative sodium current traces recorded in a HEK293 cell permanently transfected with Y1593C hNav1.4 mutant, by depolarizing the cell to $-30 \mathrm{mV}$ from an holding potential of $-120 \mathrm{mV}$ at 0.1 and $10 \mathrm{~Hz}$ stimulation frequency, before and during application of $1 \mathrm{mM}$ mexiletine. Note the use-dependent current reduction in absence of drug. (B-F) The concentration-response relationships were constructed at 0.1 and $10 \mathrm{~Hz}$ frequency stimulation, and fitted with a first-order binding function (Eq. 1 in Materials and Methods). Each point is the mean \pm SEM from at least three cells. The calculated $I_{50}$ and $I_{\max }$ values \pm SE of the fit are reported in Table 2. The slope factors ranged between 0.69 and 1.76 .

of electrostatic coupling may contribute to weaken the interaction of the aromatic tail of HMM/bHMM with the low-affinity receptor. Such a hypothesis is supported by the low energy coupling value $(<1 \mathrm{kcal} / \mathrm{mol}$ ) for tonic block by HMM and bHMM. Most probably, other parameters, including hydrophobicity, should be however involved to explain the large difference in tonic block exerted by HMM and bHMM. In addition, we observed that both HMM and bHMM exert a lower tonic block of F1586C channel with respect to mexiletine and $\mathrm{pHM}$, indicating that substituents on HMM and bHMM have additional effects to those resulting from the suppression of aromatic side chain at position 1586.

The compound pHHMM shows an electrostatic potential similar to HMM/bHMM, and tonic block was similarly reduced twofold by F1586C. Quite surprisingly, the mutation had no significant effect on pHHMM use-dependence, indicating that the drug does not bind to F1586 at all. This latter observation suggests that F1586 is no more involved in the higher-affinity binding of pHHMM.
A Tonic block

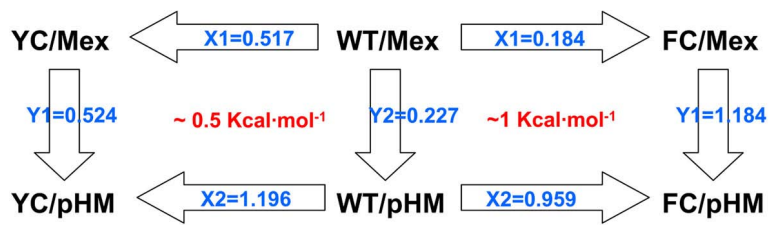

\section{B Use-dependent block}

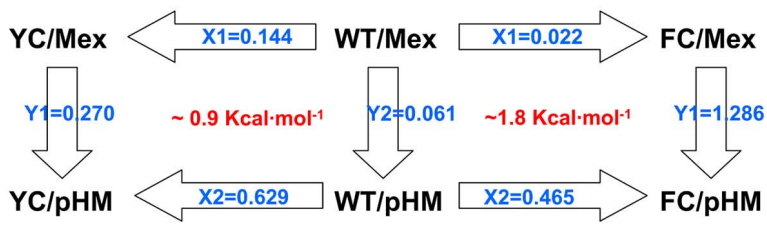

FIGURE 7 | Mutant cycle analysis of mexiletine and pHM binding to the wild-type hNav1.4 channel and its mutants Y1593C and F1586C. Mutant cycle analysis for tonic block considers $\mathrm{IC}_{50}$ values calculated at $0.1 \mathrm{~Hz}$ stimulation frequency $(\mathbf{A})$, while $\mathrm{IC}_{50}$ calculated at $10 \mathrm{~Hz}$ stimulation frequency allowed mutant cycle analysis for use-dependent block (B). The $X_{i}$ and $Y i$ values represent the changes in affinity with each mutation, calculated as the ratio of $\mathrm{IC}_{50}$ values. The coupling constant $\Omega$ is calculated as the $X 1$ to $X 2$ ratio and the coupling energy $\Delta G$ is calculated as $R T \cdot \ln \Omega$, where $R$ is the perfect gas constant (8.314 $\mathrm{J} \mathrm{K} \mathrm{mol}^{-1}$ ) and $T$ the temperature expressed in Kelvin $\left(295.15 \mathrm{~K}=22^{\circ} \mathrm{C}\right)$. The calculated $\Delta G$ shown in red was converted to kilocalorie per mole.

Table 3 | Coupling energy $(\Delta G, \mathrm{kcal} / \mathrm{mol}$ ) calculated from mutant cycles, as shown in Figure 7.

\begin{tabular}{llllll}
\hline \multirow{2}{*}{ Drug } & \multicolumn{2}{c}{ Tonic block } & & \multicolumn{2}{c}{ Use-dependent block } \\
\cline { 2 - 3 } \cline { 5 - 6 } & F1586 & Y1593 & & F1586 & Y1593 \\
\hline pHM & 0.97 & 0.49 & & 1.79 & 0.87 \\
HMM & 0.75 & 0.50 & & 1.60 & 0.78 \\
bHMM & 0.49 & 0.35 & & 1.53 & 0.73 \\
pHHMM & 0.52 & 0.50 & & 2.00 & 1.15 \\
\hline
\end{tabular}

\section{EFFECTS OF Y1593C MUTATION ON SODIUM CHANNEL BLOCKADE BY MEXILETINE AND HYDROXYLATED DERIVATIVES}

The tyrosine in position 1593 was originally individuated as an important component of the intimate drug-receptor interaction, possibility through hydrophobic interaction with the aromatic moiety of LA drugs (Ragsdale et al., 1994). This hypothesis has been somewhat challenged because Y1593 mutations can modify sodium channel gating, which rends difficult the interpretation of pharmacological results. In addition to various effects on steady-state activation and inactivation, a slowing of recovery from inactivation has been reported (O'Reilly et al., 2000; Xiao et al., 2001), which may explain the use-dependent reduction of Y1593C currents we observed in the absence of drug. Recently, the contribution of Y1593 to $\pi$-cation or $\pi-\pi$ interactions with lidocaine 


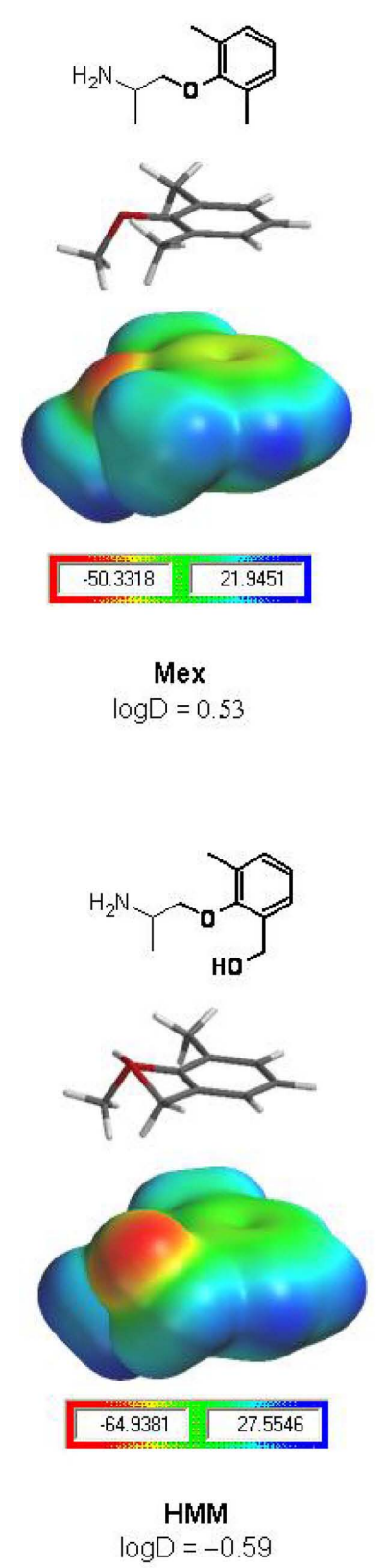

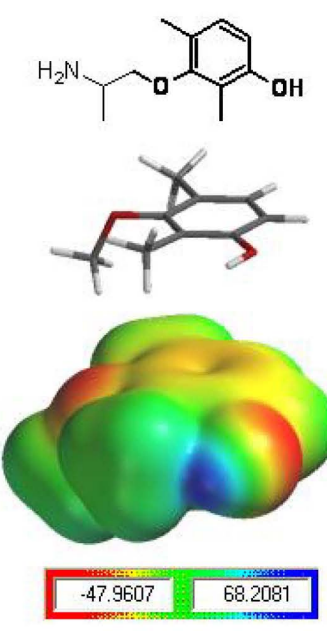

$\mathrm{mHM}$

$\log \mathrm{D}=0.02$<smiles>CC(N)COc1c(CO)cccc1CO</smiles>
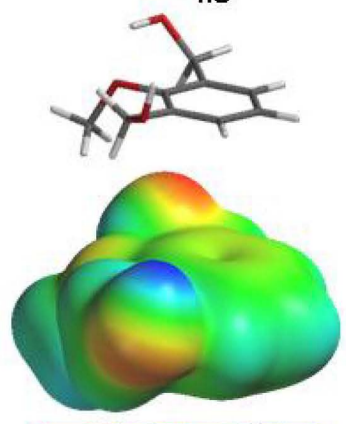

$\begin{array}{ll}-62.6450 & 59.4467\end{array}$

bHMM

$\log \mathrm{D}=-0.85$

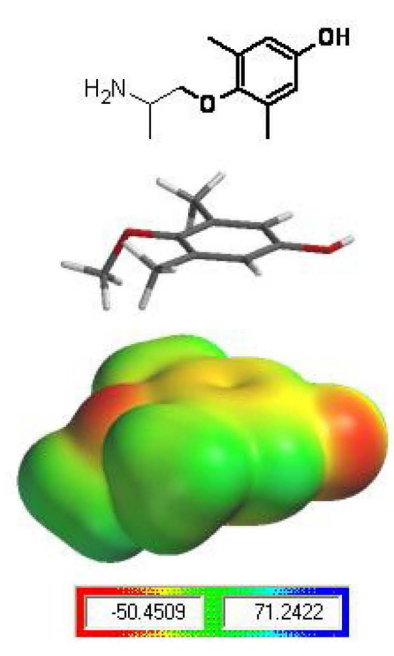

$\mathrm{pHM}$

$\log \mathrm{D}=-0.05$<smiles>Cc1cc(O)cc(CO)c1OCC(C)N</smiles>
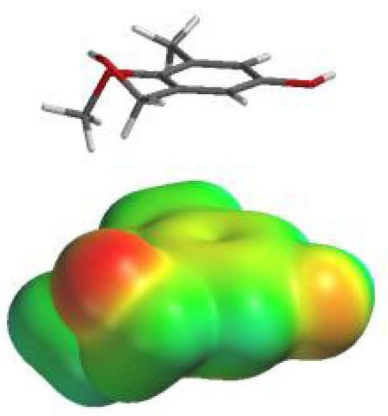

\begin{tabular}{ll}
-65.0506 & 75.8715 \\
\hline
\end{tabular}

pHHMM

$\log \mathrm{D}=-1.27$
FIGURE 8 | Calculation of drug electrostatic potential. Mexiletine and its hydroxylated analogs are displayed as chemical structures presenting in bold the moiety studied by $a b$ initio calculations (upper panels). For each compound, both the corresponding HF/3-21G* minimized three-dimensional structure and the electrostatic potential map is given in equatorial and lower panels, respectively. For each moiety, the scale bar indicates the electrostatic potential surface value range in kilocalorie per mole, the negative value being the one used in structure-activity evaluations. The HMM, bHMM, and pHHMM moieties (lower half of the figure) presented the most negative electrostatic potential values (around $-65 \mathrm{kcal} / \mathrm{mol}$ ), which most likely may allow less favorable interactions with electron-rich aromatic rings (e.g., F1586 or Y1593 rings), compared to the ones expected for Mex, $\mathrm{mHM}$, and $\mathrm{pHM}$ moieties with a less negative electrostatic potential (around $-50 \mathrm{kcal} / \mathrm{mol}$ ). The Log $D$ values experimentally measured at $\mathrm{pH} 7.4$ are indicated. has been ruled out by experiments using fluorinated amino acids (Ahern et al., 2008).

As for pilsicainide in a previous study (Desaphy et al., 2010), we observed that Y1593C reduced use-dependent sodium current blockade by mexiletine but to a lesser extent than F1586C.

The mutation may impede a direct interaction of Y1593 with the drug, or reduce the lipophilicity in proximity of the binding site. Thus considering Y1593 being involved either directly or indirectly on mexiletine binding, its mutation to C1593 may cooperatively reduce the strong interaction between the charged amine and F1586. The Y1593C mutation had a similar effect on mexiletine derivatives (except pHHMM), reducing use-dependence without altering tonic block. This observation indicates that Y1593 is not involved in the low-affinity binding, still in accord with 


\section{A low-affinity binding \\ B high-affinity binding

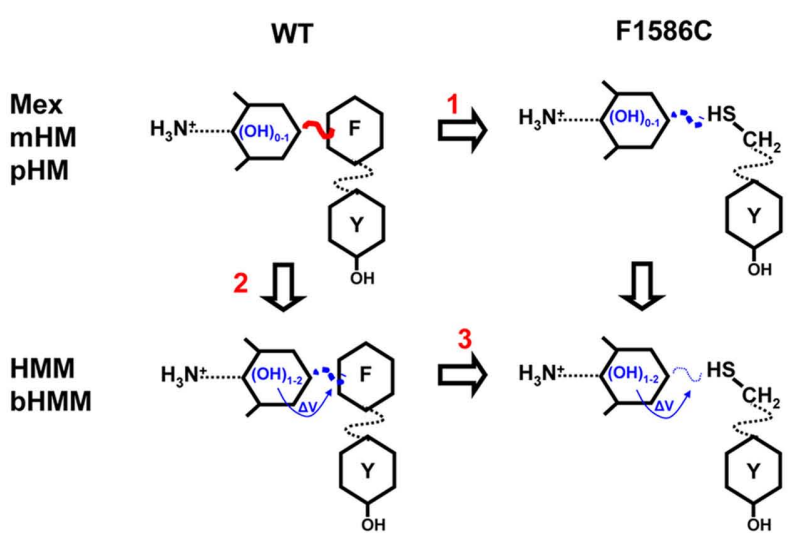 \\ FIGURE 9 | Synopsis of possible interactions of mexiletine and hydroxylated analogs with the low (A) and high (B) binding site within the wild-type hNav1.4 channel and its mutants F1586C and Y1593C. (A) \\ Regarding the low-affinity binding to closed channels, our results are in accord with an horizontal orientation of the drug, with the aryloxy moiety interacting either directly or indirectly with F1586 through electrostatic coupling. The addition of $\mathrm{OH}$ groups as in $\mathrm{mHM}$ and $\mathrm{pHM}$ does not modify aryloxy electrostatic potential thereby leaving this interaction unaltered. The F1586C mutation weakens interaction with Mex, $\mathrm{mHM}$, and pHM to the same extent (arrow 1). Introduction of $\mathrm{OH}$ as in $\mathrm{HMM}$ and bHMM weakens the interaction due to modification of aryloxy electrostatic potential and possibly other

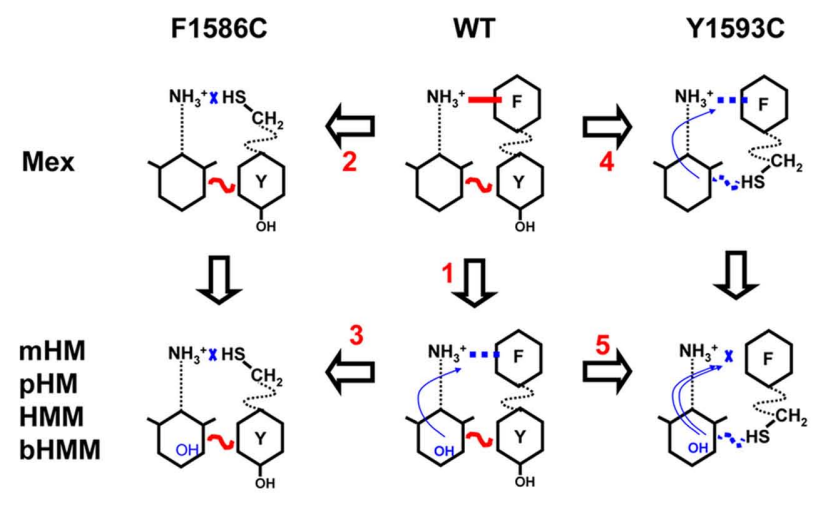 \\ parameters (arrow 2). The F1586C mutation produces additional weakening of the interaction with $\mathrm{HMM}$ and bHMM (arrow 3). Finally the Y1593C mutation has no effect on low-affinity binding (not illustrated). (B) Regarding the high-affinity binding to inactivated channels, addition of $\mathrm{OH}$ groups to the aryloxy moiety cooperatively reduced the interaction of charged amine group with F1586 (arrow 1). The amplitude of this effect depends on the $\mathrm{OH}$ position and lipophilicity. The F1586C mutation disrupts the $\pi$-cation interaction, so that $\mathrm{OH}$ substitutions have no more influence on binding (arrow 2 and 3). In contrast, the $\mathrm{Y} 1593 \mathrm{C}$ mutation impairs only partially the $\pi$-cation interaction of mexiletine through cooperativity (arrow 4). The mutation also further impairs the binding of hydroxylated analogs (arrow 5).}

the proposed position of LA drugs in the closed channel (Sheets et al., 2010). Tonic block and use-dependence of pHHMM was not altered by Y1593C, most probably because hydrophobicity is no more critical for a drug having a very negative $\log D$.

\section{SYNOPSIS}

We made an attempt to summarize the main findings in a graphical sketch (Figure 9). Regarding the low-affinity binding to closed channels (Figure 9A), our results suggest that the aryloxy moiety of drugs may interact either directly or indirectly with F1586 and suggest that electrostatic coupling is critical in

\section{REFERENCES}

Ahern, C. A., Eastwood, A. L., Dougherty, D. A., and Horn, R. (2008). Electrostatic contributions of aromatic residues in the local anesthetic receptor of voltage-gated sodium channels. Circ. Res. 102, 86-94.

Bruhova, I., Tikhonov, D. B., and Zhorov, B. S. (2008). Access and binding of local anesthetics in the closed sodium channel. Mol. Pharmacol. 74, 1033-1045.

Catalano, A., Carocci, A., Cavalluzzi, M. M., Di Mola, A., Lentini, G., Lovece, A., Dipalma, A., Costanza, T., Desaphy, J.-F., Conte Camerino, D., and Franchini, C. (2010). Hydroxylated analogs of mexiletine as tools for structural-requirements investigation of the sodium channel blocking activity. Arch. Pharm. (Weinheim) 343, 325-332.

Catalano, A., Carocci, A., Fracchiolla, G., Franchini, C., Lentini, G., Tortorella, V., De Luca, A., De Bellis, M., Desaphy, J.-F., and Conte Camerino, D. (2004). Stereospecific synthesis of "para-hydroxymexiletine" and sodium channel blocking activity evaluation. Chirality 16, 72-78.

Cavalluzzi, M. M., Catalano, A., Bruno, C., Lovece, A., Carocci, A., Corbo, F., Franchini, C., Lentini, G., and Tortorella, V. (2007). Synthesis of (R)-, (S)-, and (RS)hydroxymethylmexiletine, one of the major metabolites of mexiletine. Tetrahedron Asymmetry 18, 2409-2417.

drug binding. Regarding the high-affinity binding to inactivated channels (Figure 9B), addition of $\mathrm{OH}$ groups on the aryloxy moiety cooperatively reduced the interaction of drug charged amine group with F1586. The amplitude of this effect depends mainly on lipophilicity and also on the position of the $\mathrm{OH}$ substituent.

\section{ACKNOWLEDGMENTS}

The financial support from Telethon, Italy (non-for-profit, grants GGP04140 and GGP10101) and Association Française contre les Myopathies (non-for-profit, grant \#15020) to Diana Conte Camerino is gratefully acknowledged.

Challapalli, V., Tremont-Lukats, I. W., McNicol, E. D., Lau, J., and Carr, D. B. (2005). Systemic administration of local anesthetic agents to relieve neuropathic pain. Cochrane Database Syst. Rev. 4, CD003345.

Conte Camerino, D., Tricarico, D., and Desaphy, J.-F. (2007). Ion channel pharmacology. Neurotherapeutics 4, 184-198.

De Bellis, M., De Luca, A., Rana, F., Cavalluzzi, M. M., Catalano, A., Lentini, G., Franchini, C., Tortorella, V., and Conte Camerino, D. (2006). Evaluation of the pharmacological activity of the major mexiletine metabolites on skeletal muscle sodium currents. Br. J. Pharmacol. 149, 300-310.
De Luca, A., Natuzzi, F., Desaphy, J.-F., Loni, G., Lentini, G., Franchini, C., Tortorella, V., and Conte Camerino, D. (2000). Molecular determinants of mexiletine structure for potent and use-dependent block of skeletal muscle sodium channels. Mol. Pharmacol. 57, 268-277.

De Luca, A., Pierno, S., Liantonio, A., Desaphy, J.-F., Natuzzi, F., Didonna, M. P., Ferrannini, E., Jockusch, H., Franchini, C., Lentini, G., Corbo, F., Tortorella, V., and Conte Camerino, D. (2004). New potent mexiletine and tocainide analogues evaluated in vivo and in vitro as antimyotonic agents on myotonic ADR mouse. Neuromuscul. Disord. 14, 405-416. 
De Luca, A., Talon, S., De Bellis, M., Desaphy, J.-F., Franchini, C., Lentini, G., Catalano, A., Corbo, F., Tortorella, V., and Conte Camerino, D. (2003). Inhibition of skeletal muscle sodium currents by mexiletine analogues: specific hydrophobic interactions rather than lipophilia per se account for drug therapeutic profile. Naunyn Schmiedebergs Arch. Pharmacol. 367, 318-327.

Desaphy, J.-F., Conte Camerino, D., Franchini, C., Lentini, G., Tortorella, V., and De Luca, A. (1999). Increased hindrance on the chiral carbon atom of mexiletine enhances the block of rat skeletal muscle $\mathrm{Na}+$ channels in a model of myotonia induced by ATX. Br. J. Pharmacol. 128, 1165-1174.

Desaphy, J.-F., De Luca, A., Didonna, M. P., George, A. L. Jr., and Conte Camerino, D. (2004). Different flecainide sensitivity of hNav1.4 channels and myotonic mutants explained by state-dependent block. J. Physiol. 554, 321-334.

Desaphy, J.-F., De Luca, A., Tortorella, P., De Vito, D., George, A. L. Jr., and Conte Camerino, D. (2001). Gating of myotonic Na channel mutants defines the response to mexiletine and a potent derivative. Neurology 57, 1849-1857.

Desaphy, J.-F., Dipalma, A., Costanza, T., Bruno, C., Lentini, G., Franchini, C., George, A. L. Jr., and Conte Camerino, D. (2010). Molecular determinants of state-dependent block of voltage-gated sodium channels by pilsicainide. Br. J. Pharmacol. 160, 1521-1533.

Desaphy, J.-F., Dipalma, A., De Bellis, M., Costanza, T., Gaudioso, C., Delmas, P., George, A. L. Jr., and Conte Camerino, D. (2009). Involvement of voltage-gated sodium channels blockade in the analgesic effects of orphenadrine. Pain 142, 225-235.

Desaphy, J.-F., Pierno, S., De Luca, A., Didonna, P., and Conte Camerino, D. (2003). Different ability of clenbuterol and salbutamol to block sodium channels predicts their therapeutic use in muscle excitability disorders. Mol. Pharmacol. 63, 659-670.

Fozzard, H. A., Sheets, M. F., and Hanck, D. A. (2011). The sodium channel as a target of local anesthetic drugs. Front. Pharmacol. 2:68. doi:10.3389/fphar.2011.00068

Franchini, C., Carocci, A., Catalano, A., Cavalluzzi, M. M., Corbo, F., Lentini, G., Scilimati, A., Tortorella, P., Conte Camerino, D., and De Luca, A. (2003). Optically active mexiletine analogues as stereoselective blockers of voltage-gated $\mathrm{Na}+$ channels. J. Med. Chem. 46, 5238-5248.

Hanck, D. A., Nikitina, E., McNulty, M. M., Fozzard, H. A., Lipkind, G. M., and Sheets, M. F. (2009). Using lidocaine and benzocaine to link sodium channel molecular conformations to state-dependent antiarrhythmic drug affinity. Circ. Res. 105, 492-499.

Hidalgo, P., and MacKinnon, R. (1995). Revealing the architecture of a $\mathrm{K}^{+}$ channel pore through mutant cycles with a peptide inhibitor. Science 268 , 307-310.

Hille, B. (1977). Local anesthetics: hydrophilic and hydrophobic pathways for the drug-receptor reaction. J. Gen. Physiol. 69, 497-515.

Li, H. L., Galue, A., Meadows, L., and Ragsdale, D. S. (1999). A molecular basis for the different local anesthetic affinities of resting versus open and inactivated states of the sodium channel. Mol. Pharmacol.55, 134-141.

Lipkind, G. M., and Fozzard, H. A. (2005). Molecular modelling of local anesthetic drug binding by voltagegated sodium channels. Mol. Pharmacol. 68, 1611-1622.

McNulty, M. M., Edgerton, G. B., Shah, R. D., Hanck, D. A., Fozzard, H. A., and Lipkind, G. M. (2007). Charge at the lidocaine binding site residues Phe-1759 affects permeation in human cardiac voltagegated sodium channels. J. Physiol. 581, 741-755.

Nau, C., Wang, S.-H., Strichartz, G. R., and Wang, G. K. (1999). Point mutations at N434 in D1-S6 of m1 Na+ channels modulate binding affinity and stereoselectivity of local anesthetic enantiomers. Mol. Pharmacol. 56, 404-413.

O'Leary, M. E., and Chahine, M. (2002). Cocaine binds to a common site on open and inactivated human heart
(Nav1.5) sodium channels. J. Physiol. 541, 701-716.

O'Leary, M. E., Digregorio, M., and Chahine, M. (2003). Closing and inactivation potentiate the cocaethylene inhibition of cardiac sodium channels by distinct mechanisms. Mol. Pharmacol. 64, 1575-1585.

O'Reilly, J. P., Wang, S.-Y., and Wang, G. K. (2000). A point mutation in domain 4-segment 6 of the skeletal muscle sodium channel produces an atypical inactivation state. Biophys. J. 78, 773-784.

Pless, S. A., Galpin, J. D., Frankel, A., and Ahern, C. A. (2011). Molecular basis for class Ib anti-arrhythmic inhibition of cardiac sodium channels. Nat. Commun. 2, 351.

Ragsdale, D. S., McPhee, J. C., Scheuer, T., and Catterall, W. A. (1994). Molecular determinants of statedependent block of $\mathrm{Na}^{+}$channels by local anesthetics. Science 265 1724-1728.

Ragsdale, D. S., McPhee, J. C., Scheuer T., and Catterall, W. A. (1996). Common molecular determinants of local anesthetic, antiarrhythmic, and anticonvulsant block of voltagegated sodium channels. Proc. Natl. Acad. Sci. U.S.A. 93, 9270-9275.

Sheets, M. F., Fozzard, H. A., Lipkind G. M., and Hanck, D. A. (2010) Sodium channel molecular conformations and antiarrhythmic drug affinity. Trends Cardiovasc. Med. 20, 16-21.

Sunami, A., Glaase, J. W., and Fozzard, H. A. (2001). Structural and gating changes of the sodium channe induced by mutation of a residue in the upper third of IVS6, creating an external access path for local anesthetics. Mol. Pharmacol. 59, 684-691.

Wang, S. Y., Nau, C., and Wang, G. K. (2000). Residues in $\mathrm{Na}+$ channel D3-S6 segment modulate both batrachotoxin and local anesthetic affinities. Biophys. J. 79, 1379-1387.

Wright, S. N., Wang, S. Y., and Wang, G. K. (1998). Lysine point mutations in $\mathrm{Na}+$ channel D4-S6 reduce inactivated channel block by local anesthetics. Mol. Pharmacol. 54, 733-739.

Xiao, Y.-F., Ke, Q., Wang, S.-Y., Yang, Y., Wang, G. K., Morgan, J. P., and
Leaf, A. (2001). Point mutations in $\alpha$-subunit of human cardiac $\mathrm{Na}+$ channels alter $\mathrm{Na}+$ current kinetics. Biochem. Biophys. Res. Commun. 281, 45-52.

Yarov-Yarovoy, V., Brown, J., Sharp, E. M., Clare, J. J., Scheuer, T., and Catterall, W. A. (2001). Molecular determinants of voltagedependent gating and binding of pore-blocking drugs in transmembrane segment IIIS6 of the $\mathrm{Na}+$ channel $\alpha$ subunit. J. Biol. Chem. 276 20-27.

Yarov-Yarovoy, V., McPhee, J. C., Idsvoog, D., Pate, C., Scheuer, T., and Catterall, W. A. (2002). Role of amino acid residues in transmembrane segments IS6 and IIS6 of the $\mathrm{Na}+$ channel $\alpha$ subunit in voltage-dependent gating and drug block. J. Biol. Chem. 277, 35393-35401

Conflict of Interest Statement: The authors declare that the research was conducted in the absence of any commercial or financial relationships that could be construed as a potential conflict of interest.

Received: 26 October 2011; paperpending published: 18 November 2011; accepted: 30 January 2012; published online: 15 February 2012.

Citation: Desaphy J-F, Dipalma A, Costanza T, Carbonara R, Dinardo $M M$, Catalano A, Carocci A, Lentini G, Franchini $C$ and Camerino DC (2012) Molecular insights into the local anesthetic receptor within voltage-gated sodium channels using hydroxylated analogs of mexiletine. Front. Pharmacol. 3:17. doi: 10.3389/fphar.2012.00017

This article was submitted to Frontiers in Pharmacology of Ion Channels and Channelopathies, a specialty of Frontiers in Pharmacology.

Copyright (c) 2012 Desaphy, Dipalma, Costanza, Carbonara, Dinardo, Catalano, Carocci, Lentini, Franchini and Camerino. This is an open-access article distributed under the terms of the Creative Commons Attribution Non Commercial License, which permits noncommercial use, distribution, and reproduction in other forums, provided the original authors and source are credited. 